\title{
A CONFIGURAÇÃO DIDÁTICA PARA MEDIAÇÃO PEDAGÓGICA DO CURSO DE ESPECIALIZAÇÃO EM DOCÊNCIA PARA EDUCAÇÃO PROFISSIONAL, MODALIDADE EAD, DO INSTITUTO FEDERAL DE SANTA CATARINA
}

\author{
GAROPABA/SC MAIO/2018
Mauro Lorençatto - IFSC - mauro.lorencatto@ifsc.edu.br
Caroline Lengert - IFSC - carolinelenge@gmail.com \\ Tipo: Relato de Experiência Inovadora (EI) \\ Categoria: Métodos e Tecnologias \\ Setor Educacional: EDUCAÇÃO SUPERIOR
}

\begin{abstract}
RESUMO
Este relato refere-se à oferta do curso de pós-graduação (especialização) em Docência para a Educação Profissional do Instituto Federal de Santa Catarina (IFSC), na modalidade EaD, a partir de oferta própria do Centro de Referência em Formação e EaD (CERFEaD) do IFSC, ou seja, sem fomento do programa UAB (Universidade Aberto do Brasil) e tem como objetivo descrever a configuração do Ambiente Virtual de Ensino e Aprendizagem (moodle) para mediação pedagógica entre professor-tutor e estudantes. A configuração do AVEA definida pela equipe multidisciplinar do CERFEaD proporciona e instiga a mediação pedagógica entre professor-tutor e estudantes.
\end{abstract}

Palavras-chave: EaD; Mediação Pedagógica; Formação de Professores. 


\section{Introdução}

A Educação a Distância é uma realidade em desenvolvimento quantitativo e qualitativo. A cada ano mais cursos e turmas são ofertados e mais instituições se credenciam a oferta. Dessa forma, aumentam os formatos das propostas pedagógicas de cursos e, por consequência, as configurações didáticas de mediação pedagógica. O crescimento quantitativo é visível pelos números dos censos e pesquisas, contudo, necessitamos visualizar propostas de qualificação das mediações pedagógicas para otimizar o processo de ensino e aprendizagem e minimizar a evasão de estudantes dos cursos EaD.

A resolução do MEC n0ㅡ/2012, que estabelece as diretrizes curriculares nacionais para a educação profissional técnica de nível médio, define que a formação inicial para a docência nesta modalidade de ensino será realizada em cursos de graduação e programas de licenciatura ou outras formas, em consonância com a legislação e com normas específicas definidas pelo Conselho Nacional de Educação (BRASIL, 2012).

Os cursos de especialização são uma das possibilidades de formação de professores para a educação profissional, considerando o desafio de preparar esses profissionais, graduados em diferentes áreas, para o exercício da docência.

O Curso de Especialização em Docência para Educação Profissional, objeto deste relato, tem como desafio trabalhar uma abordagem epistemológica e didática voltadas para a educação profissional, de modo a contribuir com a formação pedagógica dos docentes que atuam ou pretendem atuar nesta modalidade de ensino.

Deste modo, foi organizada uma configuração didática para mediação pedagógica, através da educação a distância que possibilita preparar os docentes e futuros docentes para a atuação na educação profissional de nível médio.

\section{Objetivo}

Descrever a configuração didática do Ambiente Virtual de Ensino e Aprendizagem (moodle) para mediação pedagógica entre professor-tutor e estudantes no Curso de Especialização em Docência para Educação Profissional do IFSC.

\section{Referenciais Teóricos}

Grande parte dos docentes que atuam na educação profissional possuem formação 
superior em cursos de bacharelado ou tecnólogo, porém, ingressam no magistério com pouca ou nenhuma referência pedagógica sistematizada (PENA, 2016). Ao propor a formação para docência na educação profissional na modalidade a distância, destacamos a concepção de educação mediadora para a organização do trabalho pedagógico.

Nesta concepção, os materiais didáticos permitem a autonomia para o estudo e o professor é responsável pela mediação da aprendizagem, ou seja, planeja ações de interação e intervenção com os estudantes, em uma relação de proximidade (OLIVEIRA, 2006). Podemos pensar a interação sob diferentes perspectivas: a interação aluno/professor, aluno/conteúdo, aluno/aluno, professor/professor, professor/conteúdo, conteúdo/conteúdo, aluno/interface entre outras (MATTAR, 2012).

Nessa concepção, o trabalho de mediação pedagógica se concretiza a partir da construção e organização dos materiais didáticos, passando pela seleção das estratégias de ensino e sendo potencializado no trabalho de acompanhamento do estudante ao longo do seu percurso de aprendizagem (BELLONI, 2009). Nesta perspectiva, garante-se a autonomia nos estudos, mas sem descuidar do acompanhamento pedagógico, permitindo que as diferentes formas de interação aconteçam.

\section{Procedimento Metodológico}

A especialização em Docência para a Educação Profissional foi planejada na perspectiva da mediação pedagógica. Assim, o curso está organizado em módulos didáticos e inclui unidades curriculares, atividades de pesquisa e de extensão, atividades práticas de ensino e a elaboração do trabalho de conclusão de curso. O material didático das unidades curriculares são disponibilizados no ambiente virtual de ensino e aprendizagem e as avaliações presenciais são realizadas nos Núcleos de Educação a Distância (NEaDs) dos câmpus do IFSC. O calendário do curso prevê a oferta de uma unidade curricular por vez. Assim, a cada mês, o discente dedica seu tempo de estudo e envolve-se com as atividades de uma unidade curricular.

A oferta prevê turmas nos NEaDs do IFSC em diversos municípios do Estado de Santa Catarina. A turma com ingresso em 2018 está presente em nove (09) NEaDs. somando o total de 250 pós-graduandos. Como procedimento metodológico deste relato optou-se por apresentar algumas estratégias de mediação pedagógica previstas no Projeto Pedagógico do Curso (PPC) para as atividades de ensino-aprendizagem. 


\section{Docência Compartilhada}

Como a oferta deste curso prevê várias turmas simultâneas, as unidades curriculares são planejadas de forma compartilhada, envolvendo mais de um professor. $O$ planejamento do conteúdo didático e das atividades de aprendizagem: exercícios e atividades práticas, chats, fóruns de discussão, avaliações presenciais e a distância é realizado em conjunto pelos professores, possibilitando a construção coletiva do trabalho pedagógico.

O acompanhamento dos discentes ao longo da unidade curricular também é responsabilidade dos professores. Cada professor é responsável por uma ou mais turmas e faz o trabalho de mediação pedagógica, auxiliando os discentes ao longo do percurso de aprendizagem, realizando um atendimento mais personalizado e efetivo durante o tempo de estudos da unidade curricular.

O acompanhamento docente é realizado através de mensagens individuais aos discentes, ou por meio do Mural de Notícias ou do Fórum de Dúvidas, disponibilizados em cada unidade curricular no ambiente virtual de ensino e aprendizagem. Os professores também são responsáveis por acompanhar os acessos dos discentes ao conteúdo - livro didático, materiais complementares - e a realização das atividades propostas.

\section{Tutoria a Distância}

Na docência compartilhada, os próprios professores atuam como tutores a distância em sua unidade curricular, acompanhando o desempenho discente nas atividades no Ambiente Virtual de Ensino e Aprendizagem (AVEA). Todas as interações, respostas às dúvidas, feedback das atividades são realizadas pelos professores, utilizando o ambiente virtual.

\section{Interações Síncronas}

As interações síncronas acontecem por webconferência a cada quinze dias, conforme plano de aulas de cada unidade curricular. Para as webconferências utiliza-se a plataforma de conferênciaweb da Rede Nacional de Ensino e Pesquisa (RNP). A utilização da webconferência permite que os discentes participem das aulas de qualquer local e dispositivo com acesso à internet. Os encontros síncronos possibilitam que os professores apresentem aspectos relevantes do conteúdo que está sendo estudado, enfatizem e pontuem as questões mais importantes e também respondam dúvidas 
apresentadas pelos estudantes via chat (disponível na plataforma de webconferência da rede RNP) durante o tempo da aula que ocorrem nas quintas-feiras das $13 \mathrm{~h} 30 \mathrm{~min}$ às 17h30min. Além da webconferência, há também o Chat do AVEA como ferramenta para mediação pedagógica síncrona.

\section{Interações Assíncronas}

As interações assíncronas acontecem através do mural de notícias, fórum de dúvidas, fóruns com atividades de aprendizagem, através de mensagens enviadas pelos professores no início da unidade curricular, no decurso dos estudos e no fechamento das atividades. Podemos citar alguns tipos de mensagens enviadas: boas vindas e motivação para os estudos; orientações para realização de leituras e atividades; chamada a ação para os estudantes que não estão acessando o AVEA; lembretes para os prazos; de avaliação e feedback; de encerramento. Enfatiza-se o aspecto de mediação entre docentes e discentes no texto e formato das mensagens, nas quais procura-se acolher os estudantes, para que se sintam próximos, tanto dos colegas quanto dos docentes.

\section{Avaliações Presenciais}

Estas acontecem, aproximadamente, a cada dois meses e são realizadas nos NEaDs de oferta do curso. Cada NEaD organiza laboratório(s) de informática para receber os discentes e aplicar a avaliação que, segundo legislação, deve ser presencial. Para tanto, os estudantes assinam a lista de presença que é enviada à Coordenação do Curso.

Os estudantes têm acesso às avaliações (geralmente são realizadas duas por data) através do ambiente virtual. Elas podem ser um questionário formado por questões objetivas. Assim sendo, o aluno responde na própria plataforma (moodle). Também podem ser um questionário com questões dissertativas. Dessa forma, o estudante executa o download da avaliação (arquivo), elabora suas respostas, salva esse arquivo com seus nome completo em formato .PDF e realiza o upload no espaço destinado na respectiva unidade curricular. O professor, através do AVEA, acessa a prova do estudante, avalia e dá seu feedback no própria ferramenta (Envio de Tarefa) utilizada para postagem da avaliação do estudante.

\section{Apresentação dos Resultados}

Apresentamos algumas imagens que ilustram a configuração pedagógica do AVEA do curso planejada para possibilitar a interação no ambiente e também a mediação entre 
professor-tutor e estudantes ao longo do curso. O design institucional do moodle tem 0 formato de salas virtuais divididas em Suporte Acadêmico e Unidades Curriculares. Essas imagens foram retiradas das salas virtuais do "Suporte Acadêmico" e das unidades curriculares: "Introdução à EaD e AVEA" e "História, Estrutura e Políticas da Educação Profissional no Brasil”, ministradas até o momento para a turma 2018. O suporte acadêmico é um espaço voltado para Informações Gerais sobre o Curso, contatos da coordenação e do suporte do moodle, Mural de Notícias da Coordenação e o Fórum Fale com a Coordenação. Além disso, é o Espaço do Estudante onde encontra o PPC do curso, o Guia do Estudante e o Cronograma Geral do Curso. Também consta o Requerimento Padrão e a Gravação da Aula Inaugural.

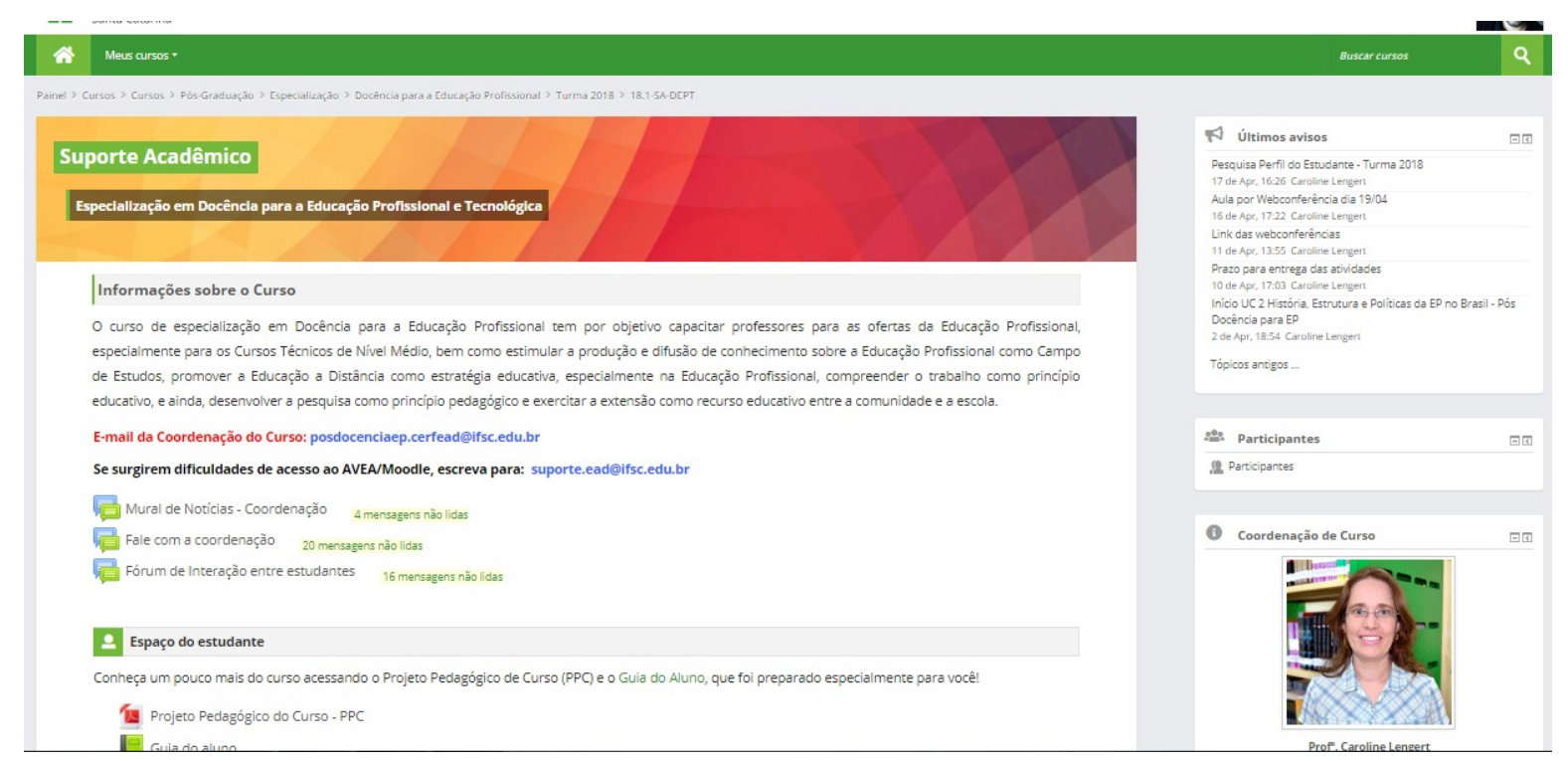

Figura 01: Sala Virtual do Suporte Acadêmico do Curso

Cada unidade curricular tem sua sala virtual. Dentro da sala o design está definido por seções: Início - Tópicos - Encerramento. Veja a seguir os espaços de cada seção e as imagens ilustrativas.

\section{Seção INÍclO:}

a) Orientações Iniciais: mural de avisos - fórum de dúvidas - fórum de discussão não avaliativo. 


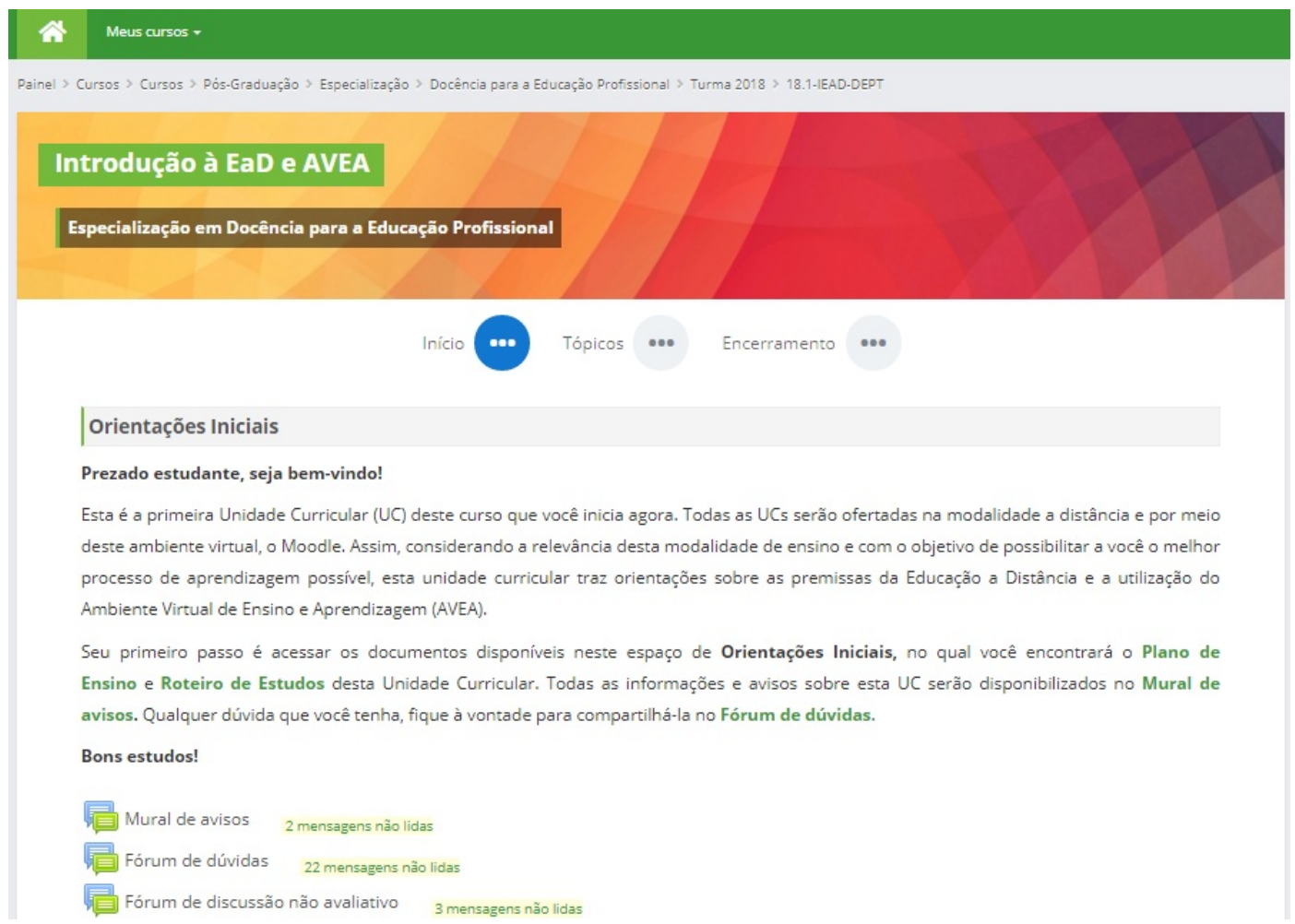

Figura 02: Sala Virtual de Unidade Curricular do Curso - seção Início I

b) Documentos da UC: Plano de Ensino e Roteiro de Estudos;

c) Webconferência: gravações;

d) Docentes: apresentação e turma responsável.

Documentos da Unidade Curricular

Conheça o Plano de Ensino e o Roteiro de Estudos para conduzir-se com autonomia pelos conteúdos e atividades propostos.

U⿴囗十 Plano de Ensino

Roteiro de Estudos

Webconferência

A webconferência será no dia 22 de março, das $13 \mathrm{~h} 30$ até as $16 \mathrm{~h}$. Esperamos a sua participação!

Link para acessar a webconferência

Oculto para estudanters

Webconferência gravada

Docentes

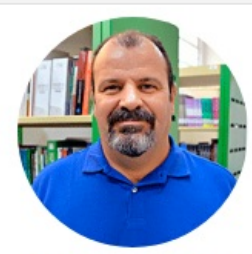

Prof. Eli Lopes da Silva

Turmas: Garopaba, Joinville, São Carlos, São Miguel do Oeste, Tubarão e Urupema.

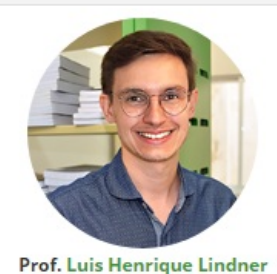

Turmas: Araranguá, Chapecó e Itajaí. 
Figura 03: Sala Virtual de Unidade Curricular do Curso - seção Início II

\section{Seção TÓPICOS:}

a) Número do tópico: apresentação;

b) Material Didático: livro didático e material complementar.

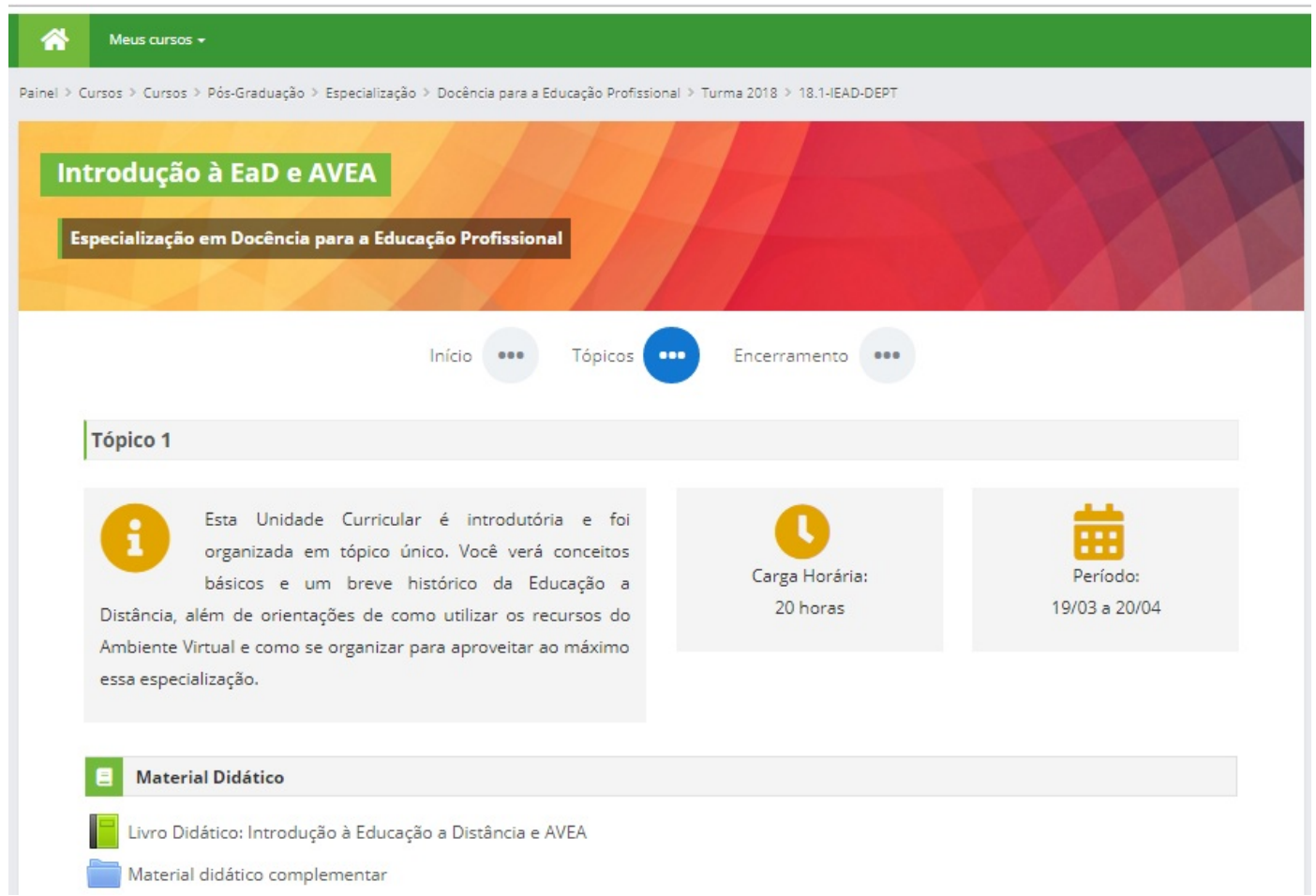

Figura 04: Sala Virtual de Unidade Curricular do Curso - seção Tópicos I

c) Atividades de Aprendizagem e Avaliação;

d) Avaliação Presenciais;

e) Avaliação Presencial de Recuperação 
Primeira tarefa avaliativa: Inserindo informações pessoais no seu perfil Página

Segunda atividade avaliativa: Questionário sobre Moodle

Terceira tarefa avaliativa: Envio do arquivo com resumo dos Capítulos 1 a 3

Quarta tarefa avaliativa: Participação no fórum de avaliação

307 mensagens não lidas

Avaliações Presenciais

Avaliação Presencial - dia 17/05

Oculto para estudantes

Avaliação Presencial 2a chamada- dia 14/06

Oculto para estudantes

Avaliação Presencial de Recuperação

Avaliação de Recuperação (28/06 - somente para alunos com média abaixo de 6,0)

Oculto para estudantes

Figura 05: Sala Virtual de Unidade Curricular do curso - seção Tópicos II

\section{Seção ENCERRAMENTO:}

\section{a) Avaliação do Docente pelo Discente.}

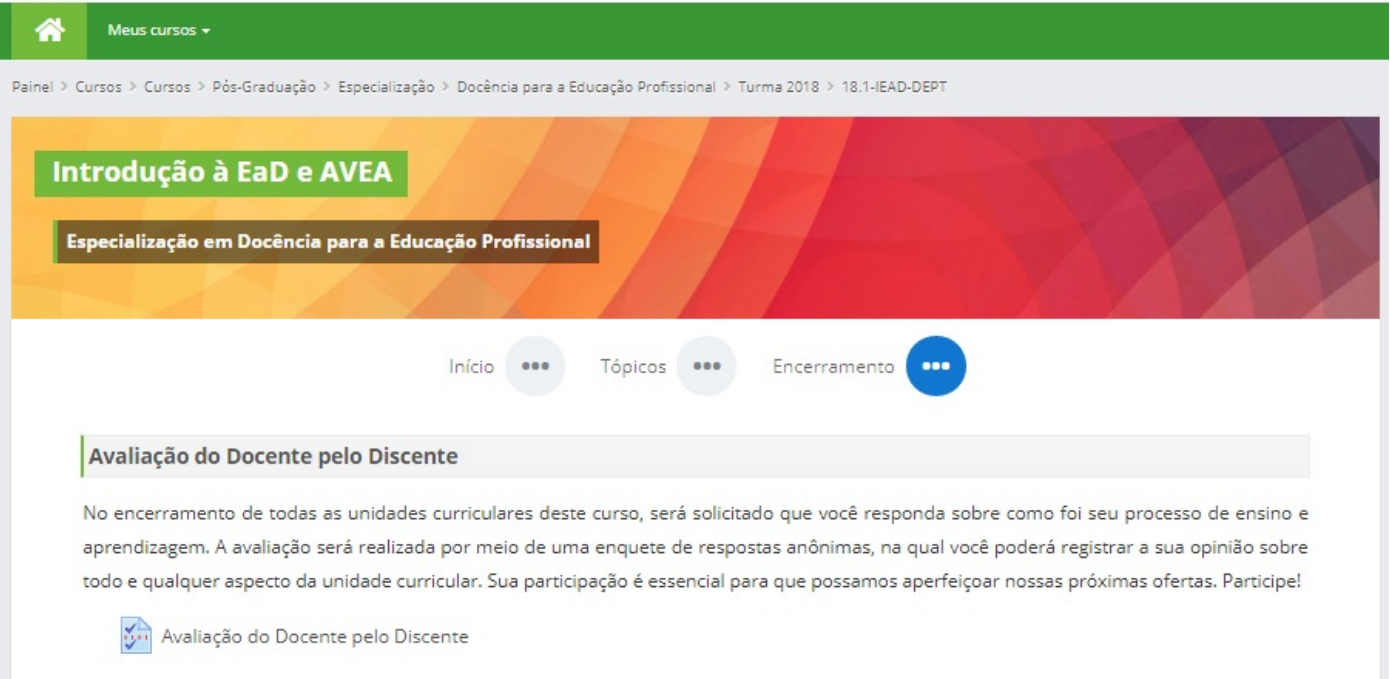

Figura 06: Sala Virtual de Unidade Curricular do curso - seção Encerramento

\section{Considerações Finais}

Diante da apresentação dos resultados do relato a principal consideração é que a 
configuração didática do Ambiente Virtual de Ensino e Aprendizagem proporciona e instiga a mediação pedagógica entre professor-tutor e estudantes no Curso de Especialização em Docência para Educação Profissional do IFSC.

Essa mediação pedagógica ocorre por meio de interação ou intervenção. Entendemos que há uma sutil mas importante distinção entre essas formas de mediação pedagógica. A interação se se constitui pela troca de informações que se encerram neste ato (mural de notícias e fórum de dúvidas) e a intervenção ultrapassa a troca de informações em si e atingem o estado de perturbação (no sentido de tirar da zona de conforto) no processo de ensino e aprendizagem (webconferência, chat, mensagem individuais, fórum de discussão e feedback de atividade e de avaliação), pois promove no professor e, principalmente, no aluno um movimento de questionamento sobre o próprio conhecimento que foi narrado no ambiente virtual.

\section{Referências}

BELLONI, Maria Luiza. Educação a distância. 5.ed. Campinas: Autores Associados, 2009.

BRASIL. MEC.CNE/CEB. Resolução ํo 06/2012. Diretrizes Curriculares Nacionais para a Educação Profissional Técnica de Nível Médio. Brasília: MEC, 2012

MATTAR, João. Tutoria e interação em educação a distância. São Paulo: Cengage Learning, 2012.

OLIVEIRA, Gleyva Maria Simões de. 0 sistema de tutoria na educação a distância. Cuiabá, NEAD/UFMT - 2006

PENA, Geralda Aparecida de Carvalho. Prática Docente na Educação Profissional e Tecnológica: os conhecimentos que subsidiam os professores de cursos técnicos. Formação Docente, Belo Horizonte, v. 09, n. 15, p. 79-94, ago./dez. 2016. Disponível em: http://formacaodocente.autenticaeditora.com.br/artigo/exibir/21/133/1. Acesso em: 18 abr 2018.

Projeto Pedagógico de Curso. Especialização em Docência para a Educação Profissional. Florianópolis: IFSC, 2016. 